\title{
CONTORNOS DA GESTÃO ESCOLAR NO BRASIL1
}

\author{
Cristiane Machado2 \\ Maria Helena Bravo3
}

\section{RESUMO}

Este artigo explora as respostas dos questionários contextuais dos diretores na Prova Brasil de 2007 e 2015 com o objetivo de analisar informações relativas ao perfil dos diretores e às práticas de gestão escolar democrática por eles declaradas. O tratamento das informações arquivadas nos microdados do banco de dados do Inep foi realizado por meio do software R. Os resultados do estudo apontam para um perfil do gestor escolar brasileiro majoritariamente do sexo feminino (80\%), com ensino superior $(94,08 \%)$, formado há mais de 8 anos $(77,5 \%)$ e com especialização (74,5\%). Destaca-se a redução do percentual de diretor que ingressou no cargo por meio de eleição (36,8\% em 2007 e 32,1\% em 2015), o aumento de acesso ao cargo por indicação (42,8\% em 2007 e 51\% em 2015) e, em 2015, a opção de concurso como alternativa para ingresso no cargo, sendo que o estado São Paulo se sobressai com $35,9 \%$ dos diretores concursados.

Palavras-chave: Gestão escolar. Diretores escolares. Questionário contextual.

\section{OUTLINES OF SCHOOL MANAGEMENT IN BRAZIL}

\begin{abstract}
This article explores how the answers of the contextual questionnaires of the principals in Proof Brasil 2007 and 2015 with the objective of analyzing yhe information described in the principals profile and the democratic school management practices declared by them. The information stored in the Inep database microdata was processed using the $\mathrm{R}$ software. The results of the study point to a profile of the mostly female Brazilian school manager (80\%), with higher education (94,08\%), graduated more than 8 years ago $(77.5 \%)$ and with specialization $(74,5 \%)$. To highlight the reduction in the percentage of directors who enter unloaded by selection (36.8\% in 2007 and $32.1 \%$ in 2015), or increased access to cargo by appointment (42.8\% in 2007 and $51 \%$ in 2007). 2015) and, in 2015, an alternative tender option for in-flight admission, with the state of São Paulo standing out with $35,9 \%$ of the directors hired.
\end{abstract}

Keywords: School management. School directors. Contextual questionnaire.

\footnotetext{
1 Versão revista e ampliada de comunicação apresentada na $38^{a}$ Reunião Nacional da Anped, realizada na UFMA - Universidade Federal do Maranhão, São Luís, Maranhão, de 01 a 05 de outubro de 2017.

2 Doutora em Educação. Docente no Departamento de Políticas, Administração e Sistemas Educacionais - DEPASE, da Faculdade de Educação da UNICAMP. Líder do Laboratório de Gestão Educacional - LAGE. Orcid iD: http://orcid.org/0000-0002-3522-4018. E-mail: crimacha@unicamp.br

${ }_{3}^{3}$ Mestre em Educação na Faculdade de Educação da USP. Participa do Grupo de Estudos e Pesquisas em Avaliação Educacional - Gepave na FEUSP. Orcid iD: http://orcid.org/00000001-5077-8839. E-mail:mh.bravo@yahoo.com.br
} 


\section{CONTORNOS DE LA GESTIÓN ESCOLAR EM BRASIL}

\section{RESUMEN}

Este artículo explora cómo las respuestas de los cuestionarios contextuales de los directores en Prova Brasil 2007 y 2015 con el objetivo de analizar la información descrita en el perfil de los directores y las prácticas democráticas de gestión escolar declaradas por ellos. La información almacenada en los microdatos de la base de datos Inep se procesó utilizando el software R. Los resultados del estudio apuntan a un perfil de la directora escolar brasileña en su mayoría femenina (80\%), con educación superior (94,08\%), graduados hace más de 8 años $(77,5 \%)$ y con especialización (74,5\%). Es de destacar la reducción en el porcentaje de directores que ingresan descargados por selección (36,8\% en 2007 y 32,1\% en 2015), o un mayor acceso a la carga por nombramiento $(42,8 \%$ en 2007 y $51 \%$ en 2015$)$ y, en 2015, una opción de licitación alternativa para la admisión, destacando el estado de São Paulo con el 35,9\% de los directores contratados.

Palabras clave: Gestión escolar. Directores escolares. Cuestionario contextual.

\section{INTRODUÇÃO}

O debate em torno da gestão escolar vem logrando espaço na literatura educacional, especialmente, após a retomada do princípio do Estado democrático com a promulgação da Constituição de 1988 e a subsequente aprovação da Lei de Diretrizes e Bases da Educação Nacional (Lei Federal 9394/96). Estes dispositivos legais demarcaram os pressupostos e regras de organização dos sistemas de ensino em uma perspectiva democrática, direcionando particular atenção à gestão escolar e, ao mesmo tempo, potencializaram as reflexões em torno do perfil necessário para o atendimento das novas demandas impostas à escola pelas transformações sociais e políticas no contexto da redemocratização.

Estudos da área de educação vêm registrando uma ampla relevância de investigação da temática da gestão escolar, à luz dos princípios de valorização dos profissionais da educação e da gestão democrática do ensino público. Observa-se grande diversidade de concepções e de abordagens em torno do tema e seus desdobramentos, abordando perfis e práticas de diretores em relação à construção de processos de autonomia escolar em termos organizacionais, administrativos e pedagógicos, formas de participação, dentre outros. 
Neste escopo, no presente artigo tem-se como propósito apresentar e analisar dados de perfil e informações sobre práticas de gestão escolar democráticas, tomando como base as respostas fornecidas por diretores de escolas brasileiras aos questionários contextuais da Prova Brasil de 2007 e de 2015.

Para a análise de perfil dos diretores escolares - compreendendo perfil como a representação de um determinado objeto e/ou fenômeno por um de seus lados e diretor como "um cargo, uma função na estrutura organizacional das instituições educativas" (WERLE, 2001, p. 149) -, foram selecionadas as questões referentes a sexo, faixa etária, raça, escolaridade, tempo entre a obtenção da maior escolaridade e a atuação no cargo, tempo de experiência no cargo de diretor, tempo como diretor na mesma escola, tempo de experiência na área da educação, tipo de instituição de obtenção da formação em nível superior, tipo de curso realizado (se presencial ou a distância), formação em nível de pós-graduação, remuneração, dedicação à direção (se exclusiva ou não) e forma de ingresso no cargo de diretor, itens considerados como elementos que compõem a representação destes profissionais e, portanto, podem configurar seu perfil.

Em relação às práticas de gestão democrática - compreendidas como processos, políticas e ações administrativas construídas no interior da instituição educativa que, por sua vez, assentam-se no "envolvimento de integrantes da comunidade escolar em decisões do cotidiano dos estabelecimentos de ensino" (WERLE, 2009, p. 140) -, foram selecionadas questões referentes à quantidade de reuniões do Conselho Escolar no ano, quantidade de reuniões do Conselho de Classe no ano, participação da equipe escolar e forma de elaboração do Projeto Político Pedagógico.

O texto está organizado em quatro partes, além desta introdução. Inicialmente, são explicitados os procedimentos metodológicos adotados; em seguida são exploradas e analisadas as respostas fornecidas pelos diretores às questões sobre perfil; na sequência as respostas fornecidas às 
questões sobre práticas de gestão democrática; e, por fim, são tecidas as considerações finais.

\section{PROCEDIMENTOS METODOLÓGICOS}

Tendo como propósito conhecer as respostas de diretores na Prova Brasil para, posteriormente, apresentá-las e analisá-las, que é o objetivo deste estudo, procedeu-se a um estudo exploratório (STAKE, 2011) das características de perfil dos diretores escolares brasileiros e de suas práticas declaradas de gestão democráticas. A utilização dos questionários contextuais da Prova Brasil, que objetivam coletar informações sobre as condições das escolas na visão dos profissionais da educação, abarcando diversas dimensões e situações que compõem o cotidiano escolar e educacional em âmbito nacional, mostrou-se adequada a essa perspectiva.

Os questionários contextuais da Prova Brasil são instrumentos com questões de múltipla escolha aplicados, na ocasião da Prova Brasil, a diretores, professores e alunos com a intenção de subsidiar estudos sobre fatores associados ao desempenho dos alunos em provas padronizadas (BRASIL, 2015). Para além destes, ainda há um questionário sobre as condições da escola que, por sua vez, é preenchido por um avaliador externo.

Na literatura da área, destacam-se estudos que investigam o potencial explicativo dos questionários quando associados aos resultados dos alunos (SOARES, 2005; MACHADO; ALAVARSE, 2014); outros que examinam as características dos questionários contextuais e de sua construção (FRANCO et al, 2003; KARINO, 2014) e outras pesquisas têm se debruçado na exploração das respostas dos questionários contextuais para associá-las a outras fontes de informação e permitir uma maior amplitude de análise dos fenômenos educacionais (CARVALHO; OLIVEIRA; LIMA, 2014).

Dessa forma, este estudo buscou examinar dados levantados pelo questionário contextual dos diretores da Prova Brasil de 2007 e 2015 com o objetivo de delinear aspectos do perfil do diretor escolar e compreender a atuação deste profissional à luz de práticas de gestão democrática 
declaradas neste instrumento, considerando tanto os limites desta análise, quanto os limites da formulação das questões e de suas respostas.

Foram selecionadas 25 questões do questionário contextual dos diretores da Prova Brasil de $2007^{4}$ e 23 questões do questionário de $2015^{5}$ que correspondiam às 25 selecionadas de 2007, para as quais realizou-se um processamento estatístico a fim de obter as frequências simples das respostas fornecidas pelos diretores. O tratamento das informações arquivadas nos microdados do banco de dados do Instituto Nacional de Estudos e Pesquisas Anísio Teixeira (Inep) foi realizado por meio do software $R$ sob a responsabilidade e execução da Empresa Júnior de Estatística da Universidade Estadual de Campinas (Unicamp) - Estat Júnior (Projeto 17022).

\section{O PERFIL DA GESTÃO ESCOLAR}

O Inep, com base nos questionários contextuais de diretores da Prova Brasil, contabilizou respostas de 47.596 diretores escolares no Brasil em 2007 e de 55.693 em 2015. Na aferição de 2007 havia quase um equilíbrio na distribuição destes diretores nas redes públicas estaduais e municipais do país: $45 \%$ (21.550) estavam lotados nas redes estaduais e 54\% (25.868) nas redes municipais. Dos respondentes apenas 36 diretores estavam lotados nas escolas federais e 14 nas escolas privadas. Observando a aferição de 2015 vemos, além de uma ampliação de 7.979 diretores, uma alteração substancial na distribuição de diretores nas redes públicas do país. Nas redes estaduais o total de diretores reduziu para $34 \%$ (19.280) e nas municipais ampliou para 62\% (34.502). Houve, também, um aumento de respondentes das escolas federais e privadas, 67 e 1.844 diretores, respectivamente.

A municipalização em curso no país, especialmente após a Emenda Constitucional 14 (Lei Federal 9424/96) que criou o Fundo de Manutenção e Desenvolvimento do Ensino Fundamental e de Valorização do Magistério FUNDEF, certamente, é o condicionante mais provável desta mudança. Essa

\footnotetext{
${ }^{4}$ Questões de perfil 2007: 1, 2, 3, 4, 5, 6, 8, 9, 11, 14, 17, 16, 20, 21, 22. Questões de gestão democrática 2007: 29, 30, 31, 32, 41, 42, 43, 44.

5 Questões de perfil 2015: 1, 2, 3, 4, 5, 6, 7, 8, 10, 11, 13, 14, 18, 19, 26. Questões de gestão democrática 2015: 24, 25, 26, 27, 28, 29, 30, 36, 37, 43.
} 
tendência foi detectada por Oliveira e Araújo (2005, p. 09) ao demostrarem, com base nos dados do censo, que em 1997 as redes estaduais abarcavam $52,9 \%$ das matrículas de ensino fundamental no país e as redes municipais $36,3 \%$, quadro que se altera em 2002, quando as redes estaduais reduziram o atendimento para $40,5 \%$ e as municipais ampliaram para $50,2 \%$ neste nível de ensino.

Em relação ao sexo dos gestores escolares, as informações corroboram pesquisas já difundidas que ressaltam a feminização da carreira docente na educação básica (VIANNA, 2002; 2013). Do total de diretores que responderam à questão em 2007, $81,97 \%$ (39.014) se declararam do sexo feminino e 17,47\% (8.316) do sexo masculino. Já os números de 2015 mostram para uma pequena movimentação neste aspecto, enquanto o total de diretores do sexo feminino recuou para 79,64\% (44.354) o do sexo masculino cresceu para 20,15\% (11.221). Embora seja notória uma pequena oscilação, para cima, no percentual masculino na carreira de 2,68\% de 2007 para 2015 , destaque-se, no entanto, que a movimentação não altera o quadro geral de feminização da carreira docente no país. Isso porque, de acordo com Vianna (2013, p. 167), a concepção de feminização do magistério tem suas raízes e implicações para além da composição sexual da categoria docente, "uma dessas implicações diz respeito ao fato de que encontramos mais homens exatamente nos níveis e modalidades de ensino que ainda oferecem maior remuneração e usufruem mais prestígio".

Neste sentido, é relevante frisar, também, estudo conduzido por Souza (2009) que analisou o perfil dos diretores com base nos dados do Saeb de 2003 e mostrou que a maioria das direções escolares era ocupada por mulheres, entretanto, elas se encontravam especialmente nas escolas de ensino fundamental e os homens nas escolas de ensino médio. Concluiu o autor que "conforme se avança nos níveis e etapas de ensino, encontra-se proporcionalmente mais homens diretores, $O$ que corresponde ao crescimento também do número de professores homens nas etapas e níveis mais avançados" (SOUZA, 2009, p. 02). 
A faixa etária predominante do diretor escolar é a que abrange as idades entre 40 e 49 anos. Quase metade dos diretores, 43,51\% (20.710) em 2007, se encontravam nesta faixa de idade e, em 2015, 42,14\% (23.468) dos diretores tinham entre 40 e 49 anos. Em seguida, a faixa etária que abriga maior número de diretores é a de 30 a 39 anos, com 26,62\% (12.671) dos diretores em 2007 e com 22,36\% (12.453) dos diretores em 2015.

Com relação à raça, de acordo com o que declararam os diretores em 2007, a branca era predominante 52,09\% (24.791 diretores), seguida de pardo 35,68\% (16.981) e pretos6 6,98\% (3.322). Em 2015, esse cenário manifestou uma diminuição do contingente de diretores que se declararam brancos para 46,55\% (25.923 diretores) e ampliou o total de diretores pardos para 40,64\% (22.633) e pretos para 8,28\% (4.610). Apesar de tímida a ampliação de pardos e pretos na gestão escolar, 6,26\% no total, somados tínhamos 42,66\% em 2007 e chegamos em 2015 com 48,92\%, os números representam a consistência das políticas afirmativas no Brasil, especialmente, no que diz respeito à instituição de cotas no ensino. Heringer (2014, p. 14), salienta que debater ações afirmativas no Brasil "significa falar de uma experiência de sucesso", que foi criada como resposta à pressão de setores da sociedade tradicionalmente discriminados e que, cada vez mais, vem se ampliando e se consolidando.

Os dados de 2007 em relação aos de 2015 indicam uma movimentação significativa na escolaridade dos diretores. Enquanto em 2007 o total de diretores com ensino superior era de 91,47\% (43.541), em 2015 , esse contingente aumentou para 94,08\% (52.405), já o total de diretores com formação em nível médio diminuiu de 7,03\% (3.344) em 2007 para 3,19\% (1.776) em 2015. Vale ressaltar que no ano de 2013 foi aprovado um projeto de lei que alterou o artigo 62 da Lei de Diretrizes e Bases da Educação Nacional (LDB 9394/96), determinando que professores com formação em nível médio aprovados em concursos para atuar na rede pública de ensino teriam o prazo de seis anos, a partir de seu ingresso nas redes públicas, para

\footnotetext{
${ }^{6}$ Manteve-se a nomenclatura utilizada nos questionários.
} 
concluir um curso de licenciatura. Contudo, educadores formados em nível médio na modalidade normal estão habilitados a lecionar na educação infantil e nos anos iniciais do ensino fundamental. De qualquer forma, esta mudança pode ter contribuído para a alteração na formação exigida para a atuação como diretor escolar.

Quando perguntados há quanto tempo os diretores obtiveram seu maior grau de escolaridade, os dados também apresentam modificações entre 2007 e 2015, possibilitando afirmar que na aferição de 2015 os diretores possuíam maior tempo entre a maior formação e a data de preenchimento do questionário em relação aos dados de 2007, denotando um intervalo maior entre a formação e a assunção ao cargo na direção. Enquanto em 2007 37,6\% (17.870) dos diretores estavam formados há mais de 15 anos e 22,2\% (10.557) entre 08 e 14 anos, em 2015 esses números aumentaram para $42,4 \%$ (23.416) e $35,1 \%$ (19.395) respectivamente. Consequentemente, observou-se, mudança considerável no contingente de diretores com menor tempo de formação. Em 2007, os diretores que estavam formados entre 3 e 7 anos perfazia um total de $28,8 \%$ (13.703), percentual que recuou para $19,6 \%$ (10.812) em 2015, já o total de diretores com menos de 2 anos de formação recuou de 10,3\% (4.888) em 2007 para 3\% (1.647) em 2015. O tempo de experiência dos diretores na área da educação manteve-se, praticamente, no mesmo patamar, em 2007, era de mais de 15 anos para 70,11\% (33.369) e, em 2015, para 71,56\% (39.857) dos gestores, provavelmente em atendimento ao dispositivo inciso $\mathrm{Vl}$, do artigo 67 da LDB 9493/96 que determina "A experiência docente é pré-requisito para o exercício profissional de quaisquer outras funções de magistério, nos termos das normas de cada sistema de ensino".

Em relação à formação em nível superior à graduação, em 2007, $57,8 \%$ diretores (27.494) afirmaram possuir especialização e $1,6 \%$ (778) mestrado e 0,3\% (152) doutorado, em 2015, com exceção da declaração de diretores com doutorado, que permaneceu em 0,3\% (182), os outros números saltaram para $74,5 \%$ (41.230) e 3,2\% (1.777), especialização e mestrado respectivamente. $O$ aumento no contingente de diretores com 
especialização foi de $16,33 \%$, que pode ser explicado pelo incremento nas exigências legais e efetivas para o cargo, além das possibilidades de progressão na carreira associadas à formação.

Esses dados apontam para um cenário onde os gestores estão assumindo o cargo com maior qualificação e experiência anterior na área da educação. Certamente, as legislações que impelem a formação em nível superior para os profissionais da educação, por um lado, e as exigências cada vez maiores e multifacetadas da profissão, contribuíram para este cenário. De acordo com Hojas (2014, p. 538), com "o aumento da população atendida nas escolas, a administração escolar foi se tornando um processo cada vez mais complexo, produzindo efeitos significativos no trabalho dos diretores escolares", impulsionando a necessidade de qualificação constante.

Tanto os dados de 2007 como os de 2015 mostram que a maioria dos diretores obteve sua formação em instituição de ensino superior privada 56,89\% (27.078) em 2007 e 59,15\% (32.945) em 2015. Em seguida, são indicadas as instituições públicas estaduais, 23,18\% (11.032) em 2007 e 23,82\% (13.266) em 2015, e as instituições públicas federais, 12,63\% (6.013) em 2007 e $13,80 \%$ (7.688) em 2015, como os locais onde as formações foram obtidas.

Em estudo sobre a atratividade da carreira docente, Gatti et al (2009) apontam que ao longo dos anos houve uma mudança no perfil socioeconômico dos que ingressam na profissão docente, sendo que a atual maioria pertencente a famílias das classes C e D. Conforme os dados consolidados nas análises do Exame Nacional do Ensino Médio de 2008, a autora aponta que estes ingressantes são, em geral, alunos provenientes dos sistemas públicos de ensino que apresentam maiores dificuldades no que tange aos conteúdos de linguagens e que tiveram dificuldades de diferentes ordens para chegar ao ensino superior. Assim, com seus poucos recursos disponíveis para investimento e acesso aos bens culturais, e seus baixos desempenhos relativos em testes padronizados e exames vestibulares, estes ingressantes, em sua maioria, traçam um percurso de formação superior através da iniciativa privada. 
A formação declarada pelos diretores foi obtida, majoritariamente, em cursos presenciais, para 82,89\% (39.451) em 2007 e 80,90\% (45.056) em 2015. Embora pequeno, é possível observar um aumento no percentual de diretores que declararam ter obtido a formação em cursos a distância, em 2007 foram 3,03\% (1.441) e, em 2015, 4,77\% (2.656), uma ampliação de 1,74\%, o que pode se configurar como uma tendência. Nesta perspectiva, valeriam novas pesquisas que aludissem sobre eventuais implicações para a atuação deste profissional na gestão escolar, uma vez que se sabe que a educação à distância se assenta em um ensino e uma aprendizagem mais flexível, interativa, dinâmica e autônoma.

A remuneração de um diretor escolar, em 2007, para 43,04\% (20.486) e em 2015 para 42,20\% (23.504), ficava entre 4 e 7 salários mínimos. A maioria dos gestores que declarou trabalhar 40 horas ou mais na direção, em 2007 , foram 92,9\% (44.217) e, em 2015, 93,62\% (52.144).

Em 2007, 69,91\% (33.275) diretores afirmaram trabalhar somente no cargo/função de diretor de escola, outros 23,1\% (10.996) tinham outra atividade na área da educação e 6,34\% (3.019) acumulavam funções fora da área da educação. Em 2015 esses números eram, respectivamente, $73,72 \%$ (41.057), 20,02\% (11.151) e 5,82\% (3.244). Esse quadro difere de estudos que apontam para uma crescente precarização do trabalho docente (OLIVEIRA, 2004) que, muitas vezes em razão dos baixos salários, impele o docente a trabalhar em mais de uma escola e, não raras vezes, mais de 40 horas semanais. Há que se destacar que os diretores, geralmente, possuem um salário superior ao do docente e, também, o cargo, comumente exige 40 horas semanais de dedicação, motivos que poderiam explicar a opção de $73,72 \%$ dos diretores, em 2015, em trabalhar somente na direção escolar.

A forma de ingresso no cargo de direção, em 2007, para 42,8\% (20.375) dos diretores foi por indicação, sendo que $21,73 \%$ (10.344) foram indicados por políticos, 10,37\% (4.937) por técnicos e 10,7\% (5.094) por outras formas. A eleição foi a forma de ingresso no cargo para $36,77 \%$ (17.500) dos diretores, sendo que 13,88\% (6.606) passaram por processo seletivo antes de serem eleitos e os demais, 22,89\% (10.894) foram diretamente eleitos. Em 2015 as 
alternativas para essa questão, no que diz respeito à indicação foram mudadas, não sendo mais possível distinguir quem indicou o diretor para o cargo. Dessa forma, 50,74\% (28.256) dos diretores foram indicados, sendo que $45,05 \%$ (25.088) somente foram indicados e 5,69\% (3.168) passaram por processo seletivo antes da indicação. Com relação ao ingresso por eleição observa-se uma redução no total de diretores que afirmaram terem sido eleitos para $31,9 \%$ (17.765), sendo que 10,62\% (5.914) passaram por processo seletivo antes de serem eleitos e os demais $21,28 \%$ (11.851) foram diretamente eleitos.

Em 2015 foi acrescida à questão a alternativa "por concurso", a qual foi escolhida por $6,48 \%$ (3.611) dos diretores respondentes. Ressalte-se que, quando observada a distribuição por estados, São Paulo se sobressai com $35,9 \%$ dos diretores concursados, respondendo, assim, por grande parte dos $6,48 \%$. Sobre esta forma de ingresso no cargo, Paro (2003, p.19), destaca que "as principais virtudes apontadas para o concurso são, pois, a objetividade, a coibição do clientelismo e a possibilidade de aferição do conhecimento técnico do candidato", ao mesmo tempo o autor faz uma crítica à forma de ingresso que abarca maior quantidade de diretores, a indicação que, em geral evidencia o caráter clientelista e patrimonialista da nossa constituição social (MENDONÇA, 2000).

Quando perguntados se participaram de atividades de desenvolvimento profissional nos últimos dois anos 88,93\% (42.329) diretores, em 2007, e 82,43\% (45.909), em 2015, responderam afirmativamente. 0 questionário perguntou, também, se o diretor promoveu atividade de formação continuada na escola. Em 2007, 57,21\% (27.230) dos diretores responderam afirmativamente e, em 2015, esse contingente aumentou para 66,38\% (36.969) dos diretores. Esta última informação, sobre a realização de atividades de formação, merece investigações mais aprofundadas que objetivem captar em que medida os gestores escolares têm adotado (ou não!) posturas que se coadunam com uma perspectiva mais política e pedagógica da gestão escolar, rompendo com a forte herança do ranço tecnicista e burocrático que fundamentou as práticas de administração 
escolar, as quais partiam do princípio de que o diretor escolar devia somente desempenhar papel mando, de autoridade hierárquica da escola, com posturas verticalizadas e inflexíveis (WERLE, 2001, p. 155).

\section{PRÁTICAS DEMOCRÁTICAS DA GESTÃO ESCOLAR}

Condição para o cumprimento e efetivação da gestão democrática, o tema da participação nas escolas tem seu lugar de destaque nos debates acadêmicos sobre gestão democrática. Conforme assevera Paro (2008, p. 16), é "absurda a proposição de uma gestão democrática que não suponha a comunidade como sua parte integrante".

O Conselho de Escola, um dos principais mecanismos de participação legalmente instituídos no âmbito da educação pública, apresenta como objetivo socializar e partilhar temas e debates que permeiam o cotidiano educacional, conforme orientação do Art. 205 da Constituição Federal de 1988 que normatiza "a educação, direito de todos e dever do Estado e da família, será promovida e incentivada com a colaboração da sociedade" (BRASIL, 1988). A criação, estímulo e fortalecimento à existência de Conselhos Escolares é condição sine qua non para o exercício da democracia na escola.

De acordo com o artigo 14 da LDB (9394/96) os sistemas de ensino devem definir as normas da gestão democrática do ensino público na educação básica, garantindo a participação dos profissionais da educação na elaboração do projeto pedagógico da escola e da comunidade em conselhos escolares. Contudo, é preciso ressaltar que não necessariamente a normatização estabelecida pela lei é capaz de produzir, por si só, Conselhos Escolares deliberativos, paritários e participativos, considerando que, em muitos casos, este espaço de participação se configura como meramente burocrático e esvaziado de funções (ARELARO; JACOMINI; CARNEIRO, 2016). Dessa forma, não são excludentes as formas de participação de estudantes, professores e funcionários que busquem junto aos governos municipais, estaduais e federais a efetivação das 
regulamentações e das garantias legais no que tange a gestão democrática de escolas e sistemas.

Nesse contexto, quando perguntados quantas vezes o Conselho Escolar se reuniu no ano, a maior parte dos diretores indica que foram três vezes ou mais, com 66,93\% (31.858) das respostas em 2007 e com 65,04\% (36.225) em 2015. No entanto, 1,79\% (852) dos diretores em 2007 e 1,78\% (992) afirmaram que esse colegiado não se reuniu nenhuma vez no ano da coleta de informações e outros 11,43\% (5.439) de diretores em 2007 e 8\% (4.455) em 2015 afirmaram não haver Conselho Escolar na instituição.

Sobre quem são os participantes do Conselho Escolar, em 2007, 63,51\% (30.226) dos diretores afirmaram que eram os professores, funcionários, alunos e pais/responsáveis e 14,32\% (6.817) somente professores, funcionários e pais/responsáveis, em 2015, 62,56\% (34.842) optaram pela primeira alternativa citada e 22,04\% (12.273) pela segunda. Nesta questão, é importante sublinhar que, em 2007, 14,51\% (6.905) diretores não a responderam, em 2015 esse número baixou para 0,63\% (353).

Há que se destacar, entretanto, conforme apontam Arelaro, Jacomini e Carneiro (2016, p. 1.149), para além das práticas de democracia representativa, com especial destaque aos conselhos escolares, há que se considerar a participação por meio da democracia direta, na forma de consulta pública, plebiscitos ou assembleias, por serem considerados mecanismos que concorrem para maior participação e transparência na gestão da escola.

Igualmente importante no exercício da gestão democrática é a existência do Conselho de Classe, considerada uma das instâncias colegiadas do trabalho pedagógico relevante diante de um projeto democrático (NADAL, 2012), uma vez que é formado pelos próprios professores que atuam na escola. E, da mesma forma que os Conselhos Escolares, é importante reconhecer que apenas a sua institucionalização não dá conta de torná-lo efetivamente atuante em seu papel pedagógico.

Em relação à quantidade de reuniões do Conselho de Classe, 65,19\% (31.029) dos diretores em 2007 e 63,31\% (35.257) em 2015 afirmaram que esses 
colegiados se reuniram três vezes ou mais no ano da coleta de dados. Em 2007, 13,94\% (6.636) dos diretores afirmaram não ter Conselho de Classe em suas escolas e, em 2015, 14,07\% (7.837) optaram pela mesma alternativa do questionário.

No âmbito da gestão escolar, a LDB (9394/96) versa sobre a elaboração e execução dos Projetos Político Pedagógicos da escola como sendo a primeira e principal atribuição da gestão escolar, devendo esta posicionar-se à frente de tal processo. Esta elaboração é colocada como ponto essencial do fazer coletivo escolar, uma vez que demonstra a articulação entre os aspectos políticos e pedagógicos da educação, com expectativas de aprendizagem relacionadas com os objetivos da instituição escolar, de modo que haja organização e coerência entre o pensar e o fazer pedagógico (SANTOS; FERRI; MACEDO, 2012). Nesse sentido, a forma de elaboração do Projeto Político Pedagógico e as pessoas envolvidas no processo expressam, ainda, a aderência das escolas aos princípios participativos constitucionais e configuram-se como um importante reflexo do exercício democrático nas instituições educacionais.

Sobre a elaboração do Projeto Político Pedagógico (PPP) da escola, dadas as alterações das alternativas de resposta ao longo dos anos, só é possível comparar as alternativas "não sei como foi desenvolvido" e "não existe projeto pedagógico". Assim, 2,13\% (1.016) dos diretores respondentes em 2007 e 1,83\% (1.020) em 2015 afirmaram não saber como o PPP foi desenvolvido; e outros 4,58\% (2.182) em 2007 e 2,51\% (1.398) em 2015 afirmaram não existir Projeto Político Pedagógico na escola sob sua responsabilidade.

Mesmo sem possibilidade de comparação com 2007, vale ressaltar que em 2015, 90,5\% (49.661) dos diretores apontaram que a elaboração do PPP contou com participação da equipe escolar, sendo que em 41,6\% (22.823) das escolas foi utilizado um modelo pronto com adaptações e discussão com a equipe escolar, em 41,3\% (22.660) foi elaborado um modelo próprio antes da discussão com a equipe escolar e em 7,6\% (4.178) utilizou-se um modelo próprio, mas houve discussão com a equipe escolar; e 3,6\% 
(1.955) diretores afirmaram que o PPP foi feito a partir de um modelo e sem discussão com a equipe escolar. Ainda que com indícios de centralização dos processos por meio da elaboração prévia dos modelos de Projeto Políticos Pedagógicos, a análise das respostas pode nos levar à constatação de que, mesmo de maneira incipiente, processos de participação e de construção coletiva dos objetivos da escola podem estar ocorrendo nas escolas, de modo que estes Projetos se tornem o resultado de um comportamento organizacional e valorativo, capaz de articular o sistema educacional macro-político e micro-político (BOTLER, 2015).

Por fim, consideramos importante explicitar outras questões, para além das que se referiam à participação, que nos pareceram relevantes para perscrutar o potencial democratizante das práticas da gestão escolar, já que a escola é o local privilegiado para o exercício de atitudes democráticas e é na construção de conhecimento que ela possibilita que a democracia se assenta (GRACINDO, 1995).

Quando perguntados se a escola desenvolve alguma ação para reduzir as taxas de abandono, em 2007, 24,57\% (11.693) dos gestores disseram que não haviam ações, embora o problema existisse, em 2015, esse contingente baixou para 4,11\% (2.287). Em relação às ações para reduzir a reprovação, em 2007, 20,28\% (9.651) afirmaram que embora o problema existisse, não desenvolviam nenhuma ação, em 2015, apenas 2,37\% (1.319) dos diretores optaram por esta alternativa. O questionário perguntou, também, se existiam ações de reforço escolar, em 2007, 74,87\% (35.634) diretores responderam afirmativamente e, em 2015, 87,97\% (48.992) do total de gestores.

Em 2015, 66,20\% (36.870) dos diretores afirmaram que frequentemente discutiam com os professores medidas com o objetivo de melhorar o ensino e a aprendizagem dos alunos e $26,61 \%$ (14.818) disseram que sempre ou quase sempre desenvolviam atividades neste sentido, totalizando $92,81 \%$ (51.588) dos gestores. No questionário de 2007 esta alternativa não estava presente, o que torna a possibilidade de comparação impossível, entretanto, é possível inferir que há uma consolidação do consenso em torno da 
importância de melhorar a qualidade da educação, tanto pelo fato da questão ter entrado no questionário a partir de 2013, como, também, pelo alto percentual de diretores, $92,81 \%$ somando as duas opções, que afirmou desenvolver tais estratégias.

\section{CONSIDERAÇÕES FINAIS}

Para concluir este artigo que teve o objetivo de explorar as respostas dos diretores nos questionários contextuais da Prova Brasil enfocando o cotejamento do perfil dos diretores e de suas práticas de gestão democrática em 2007 e 2015, cabe realçar alguns achados do estudo.

Em 2015, os diretores escolares no Brasil são, de acordo com o declarado nos questionários contextuais, majoritariamente do sexo feminino (80\%), com ensino superior (96,8\%), formados há mais de 8 anos $(77,5 \%)$, com especialização $(74,5 \%)$ e compõem, principalmente, as redes municipais (62\%). Quase a maioria (94\%) atua apenas na educação e, dentre estes, grande parte $(74 \%)$ tem como atividade remunerada exclusivamente a direção escolar. São informações que, na sua maioria, encontram eco em estudos e pesquisas do campo da educação e das ciências sociais, conforme destacado ao longo das análises dos dados.

Chama à atenção a redução, embora pequena, do percentual de diretor que ingressou no cargo por meio de eleição de 2007 (36,8\%) para 2015 (32,1\%), ao mesmo tempo em que, nota-se um aumento de acesso ao cargo por indicação (42,8\% em 2007 e 51\% em 2015). Por outro lado, em 2015, o concurso aparece como alternativa para ingresso no cargo, neste contexto, o estado São Paulo se sobressai com $35,9 \%$ de diretores concursados do total da rede estadual.

No marco dessa discussão, a Meta 19 do PNE 2014-2024 destaca a necessidade de se combinar critérios técnicos, de mérito e de desempenho, à consulta pública, envolvendo a comunidade escolar para o provimento de diretor de escola, tendência que vem se fortalecendo desde a década de 1990, a qual combina o caráter técnico da função do diretor com a necessidade de esse profissional só assumir por mérito demonstrado. Por isso, 
uma das estratégias do atual PNE propõe "desenvolver programas de formação de diretores e gestores escolares, bem como aplicar prova nacional específica, a fim de subsidiar a definição de critérios objetivos para o provimento dos cargos, cujos resultados possam ser utilizados por adesão" (BRASIL, 2014).

Com relação aos espaços de participação, há que se acentuar - e se surpreender - o fato de $8 \%$ dos diretores afirmarem, em 2015, não existir Conselho Escolar, descumprindo com preceitos expressos na Constituição Federal de 1988, referendados pela LDB de 1996. Se a porcentagem não assusta, afinal $8 \%$ parecem pouco, observando o correspondente em número de estabelecimentos vemos que 4.455 escolas não possuem Conselho Escolar.

A situação em relação à inexistência dos Conselhos de Classe, órgão formado pela coordenação e professores com o objetivo de analisar questões pedagógicas, é ainda mais preocupante. Em 2015, 7.837 diretores $(14,07 \%)$ escolheram a alternativa que indica não haver este Conselho na escola.

Com relação ao Projeto Político Pedagógico das escolas, observa-se diminuição no número de diretores que afirmou não existir PPP em suas escolas, de 4,58\% (2.182) em 2007 para 2,51\% (1.398) em 2015. Com relação à participação da comunidade escolar e às formas de elaboração dos PPP em 2015, destaca-se a ampliação dos processos de participação e de construção coletiva dos objetivos da escola, com potencial para constituírem-se como práticas organizacionais sólidas na articulação dos sistemas educacionais.

Pontua-se ainda, que o aumento dos percentuais em relação à existência de ações executadas pela escola para melhoria das taxas de abandono, reprovação e reforço escolar, aponta para a adoção, por parte das escolas, de perspectivas mais inclusivas, que superem as tradicionais práticas meritocráticas e de justiça escolar de caráter normativo vigentes no contexto escolar. 
Procurou-se, neste artigo, explorar, cotejar e analisar informações sobre diretores e práticas de gestão democrática no Brasil na expectativa de conhecer tendências, características, avanços e limites na compreensão da "gestão escolar não como ela pode ou deve ser, mas como ela demonstra ser" (SOUZA, 2012, p. 159).

\section{REFERÊNCIAS}

ARELARO, L. R. G.; JACOMINI, M. A.; CARNEIRO, S. R. G. Limitações da participação e gestão "democrática" na rede estadual paulista. Educação \& sociedade, vol.37, n.137, pp.1143-1158, 2016.

BOTLER, A. Repercussões das políticas educacionais na organização escolar: o fator tempo entre a autonomia e a regulação. RBPAE - v. 31, n. 1, p. 107 124 jan./abr. 2015.

BRASIL. Constituição da República Federativa de 1988. Brasília, Diário Oficial da União, 05/10/1988.

BRASIL. Lei de Diretrizes e Bases da Educação Nacional: Lei № 9.394 de 20 de dezembro de 1996. Diário Oficial da União, Brasília, 20 dez. 1996.

BRASIL. Lei n 9.424 (1996). Criação do FUNDEF - Fundo de Manutenção e Desenvolvimento do Ensino Fundamental e de Valorização do Magistério. Diário Oficial da União, Brasília, 24 dez. 1996.

BRASIL. Lei 13.005 (2014). Aprova o Plano Nacional de Educação - PNE 2014 2024 e dá outras providências. Presidência da República. Casa Civil. Subchefia para Assuntos Jurídicos. Brasília: DF, 2014.

BRASIL. Instituto Nacional de Estudos e Pesquisas. Questionários contextuais. Disponível em http://portal.inep.gov.br/web/guest/educacaobasica/saeb/instrumentos-de-avaliacao Acesso em 05 mar. 2015.

CARVALHO, C. P.; OLIVEIRA, A. C. P.; LIMA, M. de F. M. Avaliações externas: tensões e desafios para a gestão escolar. Estudos em Avaliação Educacional, São Paulo, v. 25, n. 59, p. 50-76, set./dez. 2014.

FRANCO, C. et al. O referencial teórico na construção dos questionários contextuais do Saeb 2001. Estudos em Avaliação Educacional, São Paulo, n. 28, p. 39-74, 2003.

GATTI, B. A. et al. Atratividade da carreira docente no Brasil. São Paulo: FCC, 2009. (Relatório final) 
GRACINDO, R. V. Democratização da Educação e Educação Democrática: duas faces de uma mesma moeda. Revista Ensaio, v.3, n.7, p.149-156, 1995.

HERINGER, R. Um Balanço de 10 Anos de Políticas de Ação Afirmativa no Brasil. Tomo, São Cristóvão, n. 24, p. 18-35, 2014.

HOJAS, V. F. Concurso público para diretor de escola no estado de São Paulo: expectativas dos órgãos centrais do ensino e as percepções de diretores concursados. RBPAE, Revista Brasileira de Política e Administração da Educação - v. 30, n. 3, p. 535 - 551 set./dez. 2014.

KARINO, C. A.; VINHA, L. G. do A.; LAROS, J. A. Os questionários do Saeb: o que eles realmente medem? Estudos em Avaliação Educacional, São Paulo, v. 25, n. 59, p. 270-297, set./dez. 2014.

MACHADO, C.; ALAVARSE, O. M. Avaliar para melhorar a qualidade no ensino? Potencialidades e limites dos questionários contextuais da Prova Brasil. Educação em Revista, Marília, v. 15, n. 1, p. 7-18, jan./jun, 2014.

MENDONÇA, E. F. A regra e o jogo: democracia e patrimonialismo na educação brasileira. Campinas, SP: Ed. LaPPlanE/ FE/ Unicamp, 2000.

NADAL, B. G. Cultura escolar e conselho de classe: gestão democrática do trabalho pedagógico? Práxis Educativa, Ponta Grossa, v. 7, n. 1, p. 199-225, jan./jun. 2012.

OLIVEIRA, D. A. A reestruturação do trabalho docente: precarização e flexibilização. Educação \& sociedade, Campinas, v. 25, n. 89, p.1127-1144, set./dez. 2004.

OLIVEIRA, R. P.; ARAUJO, Gilda Cardoso. Qualidade do ensino: uma nova dimensão da luta pelo direito à educação. Revista Brasileira de Educação, São Paulo, n. 28, p. 5-23, jan./abr. 2005.

PARO, V. H. Gestão democrática da escola pública. $3^{\circ}$ ed. São Paulo: Ática, 2008.

SANTOS, C. M.; FERRI, L. M. C. G.; MACEDO, M. E. C. M. de. O planejamento participativo da escola como prática inovadora. Cadernos de Educação, FaE/PPGE/UFPel. Pelotas [41]: 175 - 187, jan./fev./abr. 2012.

SOARES, J. F. O efeito da escola no desempenho cognitivo de seus alunos. In: MELLO e SOUZA, Alberto (org.). Dimensões da avaliação educacional. Petrópolis: Vozes, 2005. p. 174-204. 
SOUZA, A. R. Perfil da gestão da escola pública no Brasil: um estudo sobre os diretores escolares e sobre aspectos da gestão democrática. Revista lberoamericana de Educação, n. $49 / 2$, abril, p. 01-12, 2009.

SOUZA, A. R. A natureza política da gestão escolar e as disputas pelo poder na escola. Revista Brasileira de Educação, v. 17 n. 49 jan.-abr. p. 159-241, 2012.

STAKE, R. E. Pesquisa qualitativa - estudando como as coisas funcionam. Porto Alegre: Penso, 2011.

VIANNA, C. P. A feminização do magistério na educação básica e os desafios para a prática e a identidade coletiva docente. In: YANNOULAS, Silvia Cristina (org.). Trabalhadoras: Análise da feminização das profissões e ocupações. Brasília, DF: Abaré, 2013. p. 159-180.

VIANNA, C. P. O sexo e o gênero da docência. Cadernos Pagu [online]. 2002, n.17-18, pp.81-103. ISSN 1809-4449. http://dx.doi.org/10.1590/S010483332002000100003 . Acesso em 14 de março de 2017.

WERLE, F. O. C. Novos tempos, novas designações e demandas: diretor, administrador ou gestor escolar. RBPAE - Revista Brasileira de Política e Administração da Educação, Porto Alegre, v. 17, n. 2, p. 147-160, 2001.

WERLE, F. O. C.; MANTAY, C.; ANDRADE, A. C. Direção de escola básica em perspectiva municipal. Educação, Porto Alegre, v. 32, n. 2, p. 139-149, maio/ago. 2009.

Recebido em: 04 de agosto de 2021. Aprovado em: 30 de agosto de 2021. Publicado em: 24 de setembro de 2021.

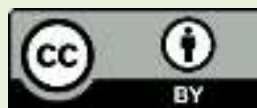

